\section{Diabietane Ether, a New Dimeric Abietane with an Ether Linkage from Taxus cuspidata Needles}

Zhi-Yu Nia ${ }^{\mathrm{a}}$, Yi-Bing $\mathrm{Wu}^{\mathrm{b}}$, Mei Dong ${ }^{\mathrm{a}}$,

Man-Li Zhang ${ }^{\mathrm{b}}$, Yu-Fang Wang ${ }^{\mathrm{b}}$, Françoise Sauriol ${ }^{\mathrm{c}}$, Chang-Hong Huo ${ }^{b}$, Qing-Wen Shib,d,

Yu-Cheng Gu ${ }^{\mathrm{b}, \mathrm{e}}$, Hiromasa Kiyota ${ }^{\mathrm{f}}$, and Bin Cong ${ }^{\mathrm{a}, \mathrm{d}}$

${ }^{a}$ College of Basic Medicine, Hebei Medical University, Shijiazhuang, 050017, Hebei Province, P. R. China

b School of Pharmaceutical Sciences, Hebei Medical University, Shijiazhuang, 050017, Hebei Province, P. R. China

c Department of Chemistry, Queen's University, Kingston, Ontario, K7L 3N6, Canada

d Hebei Key Laboratory of Forensic Medicine, Shijiazhuang, 050017, Hebei Province, P. R. China

e Syngenta Jealott's Hill International Research Centre, Bracknell, Berkshire, RG42 6EY, UK

${ }^{f}$ Graduate School of Agricultural Science, Tohoku University, Aoba-ku, Sendai 981-8555, Japan

Reprint requests to Q.-W. Shi.

E-mail: shiqingwen@hebmu.edu.cn or

H. Kiyota. E-mail: kiyota@biochem.tohoku.ac.jp

Z. Naturforsch. 2011, 66b, $1083-1086$; received July 20, 2011

Diabietane ether (1), a new abietane dimer connected by an ether linkage, and two known abietane diterpenoids ( $\mathbf{2}$ and $\mathbf{3}$ ) were isolated from the needles of Taxus cuspidata.

Key words: Taxus cuspidata, Abietanes, Diterpenes, Dimer, Structure Elucidation

\section{Introduction}

Yew trees are a significant source of paclitaxel (Taxol ${ }^{\circledR}$ ), one of the most promising drugs against ovarian and breast cancer currently under clinical use. Although more than 500 taxane diterpenoids were isolated from yew trees to date [1-3], new biologically active compounds still have to be explored. In the continuation of our investigation of the composition of yew trees, one new abietane dimer with an ether linkage and two known abietane diterpenoids were found from the needles of the Japanese yew, Taxus cuspidata Sieb. et Zucc (Fig. 1). In this paper, we report the isolation and structure elucidation of these compounds.
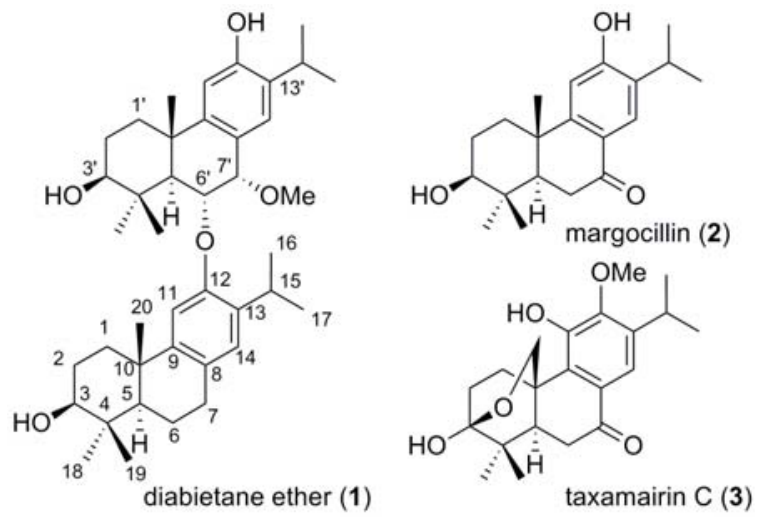

Fig. 1. Abietanes isolated from Taxus cuspidata.

\section{Results and Discussion}

Compound 1 was isolated as an amorphous solid. Its molecular formula was elucidated as $\mathrm{C}_{41} \mathrm{H}_{60} \mathrm{O}_{5}$ from HR-FABMS analysis and ${ }^{13} \mathrm{C}$ NMR spectral data (Table 1). The ${ }^{1} \mathrm{H}$ NMR spectrum showed the presence of six singlet methyl $\left(\delta_{\mathrm{H}}=0.90,0.984,1.08,1.10\right.$, $1.29,1.37)$, four doublet methyl $\left(\delta_{\mathrm{H}}=0.971,1.04\right.$, $1.14,1.19)$, one methoxy $\left(\delta_{\mathrm{H}}=3.15\right)$, and four oxymethine $\left(\delta_{\mathrm{H}}=3.27,3.27,4.01,4.88\right)$ groups. The HMBC analysis revealed that the four doublet methyl and two methine $\left(\delta_{\mathrm{H}}=3.09,3.27\right)$ signals made up two sets of isopropyl groups connected to aromatic rings (Table 1). In addition, four singlet proton signals $\left(\delta_{\mathrm{H}}=\right.$ $6.851,6.858,6.96,7.95)$ were observed in the aromatic region. These data suggested that $\mathbf{1}$ was composed of two sets of similar structural fragments. Considering the 12 degrees of unsaturation from the chemical formula and the presence of two aromatic rings, $\mathbf{1}$ had to be a dimer of a tricyclic aromatic diterpenoid. Detailed HMBC analysis revealed that both components had an abietane framework. One component, with only two oxygen (hydroxy or alkoxy) functional groups on C-3 and $\mathrm{C}-12$ positions, was identified as a hinokiol derivative [4], while the other with four oxygen functional groups on C- $3^{\prime}, \mathrm{C}-6^{\prime}, \mathrm{C}-7^{\prime}$, and $\mathrm{C}-12^{\prime}$ has not been reported to date. Then, the connectivity of the two abietane fragments was clarified by the HMBC correlation from $\mathrm{H}-6^{\prime}$ to $\mathrm{C}-12$. The linkage should be an ether bond because there was one extra oxygen atom in the chemical formula, and because of the low-field chemical shift value of $\mathrm{H}-6^{\prime}\left(\delta_{\mathrm{H}}=4.88\right)$ and $\mathrm{C}-12\left(\delta_{C}=152.1\right)$. The HMBC analysis also showed that one methoxy group 


\begin{tabular}{|c|c|c|c|c|c|}
\hline Position & $\delta(\mathrm{H})$ mult & $J(\mathrm{~Hz})$ & $\delta(\mathrm{C})^{\mathrm{a}}$ & $\mathrm{HMBC}^{\mathrm{b}}$ & Table $1 .{ }^{1} \mathrm{H}$ and ${ }^{13} \mathrm{C}$ NMR spectral data \\
\hline$\overline{1-e q}$ & $2.36(\mathrm{dt})$ & $12.9,3.4$ & 37.9 & & for compound 1 (500 MHz for ${ }^{1} \mathrm{H}$ and \\
\hline $1-a x$ & $1.55(\mathrm{~m})$ & & & & $125 \mathrm{MHz}$ for ${ }^{13} \mathrm{C}$, in $\mathrm{CDCl}_{3}$ ). \\
\hline 2 & $-^{c}$ & & $-^{\mathrm{c}}$ & & \\
\hline 3 & 3.27 (o.m) & & 78.1 & & \\
\hline 4 & - & & 39.3 & & \\
\hline $5-a x$ & $1.31(\mathrm{~m})$ & & 50.9 & & \\
\hline 6-eq & $1.89(\mathrm{~m})$ & & & & \\
\hline 6-ax & $1.75(\mathrm{~m})$ & & 19.7 & & \\
\hline 7-eq & $2.88(\mathrm{dd})$ & $16.4,6.3$ & 30.5 & $6,9,14$ & \\
\hline 7-ax & 2.77 (ddd) & $16.4,12.4,7.3$ & & $6,9,14$ & \\
\hline 8 & - & & 127.3 & & \\
\hline 9 & - & & 148.3 & & \\
\hline 10 & - & & 38.0 & & \\
\hline 11 & $7.05(\mathrm{~s})$ & & 108.6 & $8,9,10,12,13,15^{\mathrm{w}}$ & \\
\hline 12 & - & & 152.1 & & \\
\hline 13 & - & & 135.1 & & \\
\hline 14 & $6.858(\mathrm{~s})$ & & 127.3 & $7,9,11,{ }^{w} 15$ & \\
\hline 15 & 3.09 (sept) & 6.9 & 26.4 & & \\
\hline 16 & $1.04(\mathrm{~d})$ & 7.1 & 22.9 & $13,15,17$ & \\
\hline 17 & $0.971(\mathrm{~d})$ & 7.1 & 23.5 & $13,15,16$ & \\
\hline $18(\mathrm{eq})$ & $1.08(\mathrm{~s})$ & & 28.6 & $3,4,5,19$ & \\
\hline $19(\mathrm{ax})$ & $0.90(\mathrm{~s})$ & & 15.9 & $3,4,5,18$ & \\
\hline 20 & $1.29(\mathrm{~s})$ & & 25.2 & $5,9,1 / 10$ & \\
\hline $1-\mathrm{eq}^{\prime}$ & 2.09 (o.m) & & 37.9 & & \\
\hline $1-\mathrm{ax}^{\prime}$ & $1.68(\mathrm{td})$ & $12.5,4.6$ & & & \\
\hline $2^{\prime}$ & $-^{\mathrm{c}}$ & & $-^{\mathrm{c}}$ & & \\
\hline $3^{\prime}$ & 3.27 (o.m) & & 78.1 & & \\
\hline $4^{\prime}$ & - & & 40.2 & & \\
\hline $5^{\prime}$ & $1.57(\mathrm{~d})$ & 8.1 & 55.6 & & \\
\hline $6^{\prime}$ & $4.88(\mathrm{~d})$ & 8.1 & 78.1 & $4^{\prime}, 5^{\prime}, 7^{\prime}, 8^{\prime}, 12$ & \\
\hline $7^{\prime}$ & $4.01(\mathrm{~s})$ & & 81.9 & $5^{\prime}, 6^{\prime}, 8^{\prime}, 9^{\prime}, 14^{\prime}$ & \\
\hline $8^{\prime}$ & - & & 123.5 & & \\
\hline $9^{\prime}$ & - & & 150.5 & & \\
\hline $10^{\prime}$ & - & & 37.9 & & \\
\hline $11^{\prime}$ & $6.851(\mathrm{~s})$ & & 110.6 & $7^{\prime},{ }^{w} 8^{\prime}, 9^{\prime}, 10^{\prime}, 12^{\prime}, 13^{\prime}$ & \\
\hline $12^{\prime}$ & - & & 155.7 & & \\
\hline $13^{\prime}$ & - & & 131.4 & & \\
\hline $14^{\prime}$ & $6.96(\mathrm{~s})$ & & 130.3 & $7^{\prime}, 9^{\prime}, 10^{\prime},{ }^{\mathrm{w}} 11^{\prime},{ }^{\mathrm{w}} 12^{\prime}, 15^{\prime}$ & \\
\hline $15^{\prime}$ & 3.27 (o.m) & & 27.0 & & a The ${ }^{13} \mathrm{C}$ chemical shifts were extracted \\
\hline $16^{\prime}$ & $1.19(\mathrm{~d})$ & 6.8 & 22.8 & $13^{\prime}, 15^{\prime}, 17^{\prime}$ & from the HMQC experiment $( \pm 0.2 \mathrm{ppm})$. \\
\hline $17^{\prime}$ & $1.14(\mathrm{~d})$ & 6.8 & 22.7 & $13^{\prime}, 15^{\prime}, 16^{\prime}$ & The numbers in bold character represent \\
\hline $18^{\prime}(\mathrm{ax})$ & $1.10(\mathrm{~s})$ & & 17.3 & $3^{\prime}, 4^{\prime}, 5^{\prime}, 19^{\prime}$ & quaternary carbons whose chemical shifts \\
\hline $19^{\prime}(\mathrm{eq})$ & 0.984 (o.s) & & 29.7 & $3^{\prime}, 4^{\prime}, 5^{\prime}, 18^{\prime}$ & were obtained from the HMBC experiment \\
\hline $20^{\prime}$ & $1.37(\mathrm{~s})$ & & 25.4 & $5^{\prime}, 9^{\prime}, 1^{\prime} / 10^{\prime}$ & $( \pm 0.2 \mathrm{ppm}) ; \mathrm{b}$ intensities are marked as \\
\hline $\mathrm{OMe}$ & $3.15(\mathrm{~s})$ & & 55.0 & $7^{\prime}$ & weak $(\mathrm{w}) ;{ }^{\mathrm{c}}$ not identified. \\
\hline
\end{tabular}

is attached to C- $7^{\prime}$. Thus, C-3, C- $3^{\prime}$, and C- $12^{\prime}$ had free hydroxy groups.

The relative stereochemistry was investigated by the NOESY experiment (Fig. 2). The strong NOE correlations of $\mathrm{H}-3^{\prime} / \mathrm{H}-5^{\prime}, \mathrm{H}-6^{\prime} / \mathrm{H}-20^{\prime}$, and $\mathrm{H}-6^{\prime} / \mathrm{H}-7^{\prime}$ revealed a $3^{\prime} \beta, 6^{\prime} \alpha, 7^{\prime} \alpha$-configuration of the oxygen functions, and a $5^{\prime} \alpha-\mathrm{H}, 20^{\prime} \beta$-Me-trans-fused $\mathrm{A}^{\prime} / \mathrm{B}^{\prime}$ ring. In addition, the conformation of the ether linkage was elucidated as shown in Fig. 2 by the NOE correlations of $\mathrm{H}-11 / \mathrm{H}-6^{\prime}$ and $\mathrm{H}-11 / \mathrm{H}-\mathrm{7}^{\prime}$. The relative configuration of the hinokiol fragment was determined by compar- ing the ${ }^{1} \mathrm{H}$ NMR data with those reported $[4 b, 5]$. Accordingly, the whole structure of $\mathbf{1}$ was elucidated to be $12-O-\left(7^{\prime}-\right.$ methoxyhinokiol-6'-yl)hinokiol, named diabietane ether.

Dimeric diterpenes are of rare occurrence in nature $[6,7]$, most of them apparently arising as the results of a Diels-Alder-type reaction of two monomeric moieties [8], or of a macrodiolide or a macrocyclic hemiacetal [9]. Compound $\mathbf{1}$ appears to be particularly interesting because the two monomers are connected through a single ether linkage, which, to the best 


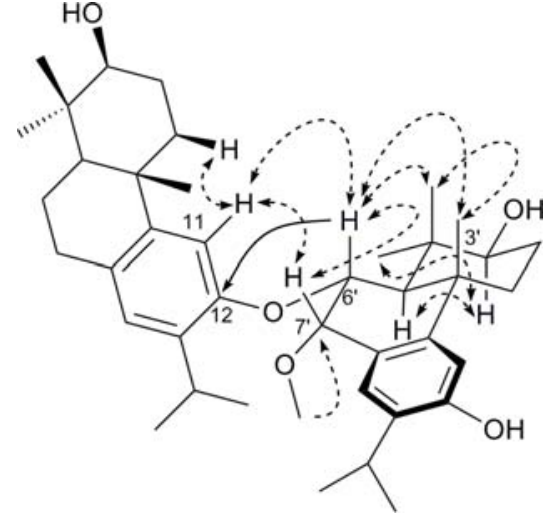

Fig. 2. Dotted arrows denote selected NOE correlations, and solid arrows indicate key HMBC correlations $(\mathrm{H} \rightarrow \mathrm{C})$ of $\mathbf{1}$.

of our knowledge, is only the second example among the dimeric diterpenes [10]. A macrodiolide [9], and dimers with two ether or hemiacetal linkages have been reported [11].

Compound 2, obtained as an amorphous powder, was identical with margocillin first isolated from neem trees Azadirachta indica [12], and also from $T$. mairei [5].

Compound $\mathbf{3}$, obtained as a colorless powder, was identical with taxamairin $C[5,13]$ isolated from the bark of T. mairei, from the bark of T. yunnanensis [14], from callus cultures of T. baccata [15], and from $T$. cuspidata [16].

\section{Experimental Section}

General

Optical rotation: Jasco DIP-370. NMR spectra: Bruker Avance-500 spectrometer. FAB-MS: Vacuum Generators ZAB-HS. Flash chromatography: Silica gel 60 (230400 mesh EM Science). Thin layer chromatography: Silica gel $60 \mathrm{~F}_{254}(0.5 \mathrm{~mm}$, EM Science). Preparative HPLC: Waters Delta Prep 3000 and UV 486 with Partisil 10 ODS-2 MAG-20 column $(22 \times 500 \mathrm{~mm})$.

\section{Plant material}

The needles of Taxus cuspidata were collected in the autumn of 2000 at Tsutsuzigaoka Park, Sendai City in the northeast of Japan. The taxonomic identification of the plant material was performed by Professor Takashi Oritani of Toyama Prefectural University, Toyama, Japan. Several voucher specimens have been conserved in the Laboratory of Applied Bioorganic Chemistry, Graduate School of Agricultural Sciences, Tohoku University, Japan.

\section{Extraction and isolation}

Air-dried needles $(3.0 \mathrm{~kg}$ ) of T. cuspidata were extracted with $16 \mathrm{~L}$ of methanol at r.t. The combined organic extracts were evaporated under reduced pressure. Water $(2 \mathrm{~L})$ was added and subsequently defatted with hexane $(3 \times 2 \mathrm{~L})$. The aqueous phase was then salted and extracted with $\mathrm{CH}_{2} \mathrm{Cl}_{2}$. The resulting $\mathrm{CH}_{2} \mathrm{Cl}_{2}$ extracts were evaporated yielding $45 \mathrm{~g}$ of a dark-green mass. A portion of the methylene chloride extract (38 g) was subjected to flash column chromatography. Successive elution with $\mathrm{CH}_{2} \mathrm{Cl}_{2}-\mathrm{MeOH}$ gradient $(5 \%$ to $45 \%)$ yielded 32 fractions $\left(\mathrm{Fr}_{\mathrm{D}-1}\right.$ to $\left.\mathrm{Fr}_{\mathrm{D}-32}\right)$ on the basis of TLC. The combined fraction of $\mathrm{Fr}_{\mathrm{D}-25}$ to $\mathrm{Fr}_{\mathrm{D}-29}$ was loaded onto a silica gel column and eluted using stepwise gradients of hexane-acetone to furnish 20 fractions ( $\mathrm{Fr}_{\mathrm{D}-25-1}$ to $\left.\mathrm{Fr}_{\mathrm{D}-25-20}\right)$. The fractions $\mathrm{Fr}_{\mathrm{D}-25-16}$ to $\mathrm{Fr}_{\mathrm{D}-25-18}$ were chromatographed over silica gel eluting with hexaneacetone $(1: 1$ and $2: 3)$ to yield 15 subfractions $\left(\mathrm{Fr}_{\mathrm{D}-25-16-1}\right.$ to $\left.\mathrm{Fr}_{\mathrm{D}-25-16-15}\right)$. Fractions $\mathrm{Fr}_{\mathrm{D}-25-16-10}$ to $\mathrm{Fr}_{\mathrm{D}-25-16-12}$ were applied to a preparative TLC, developed with hexane-acetone $(3: 4)$ to yield a residue $\left(13 \mathrm{mg}, R_{\mathrm{f}}=0.56\right)$. Further purification was achieved by preparative HPLC, eluted with a linear gradient of acetonitrile in water from $25 \%$ to $100 \%$ in $50 \mathrm{~min}$ at a flow rate of $3 \mathrm{~mL} \mathrm{~min}^{-1}$ and finally provided compound 1 ( $\left.2.0 \mathrm{mg}, t_{R}=23.2 \mathrm{~min}\right)$.

12-(3' $\beta, 12-D i h y d r o x y-7^{\prime} \alpha$-methoxy-abieta- $8^{\prime}, 11^{\prime}, 13^{\prime}$-trien$\sigma^{\prime} \alpha$-yl)oxyabieta-8,11,13-trien-3 $\beta$-ol (diabietane ether, 1)

Gum; $[\alpha]_{\mathrm{D}}^{22}=+28\left(c=0.040, \mathrm{CHCl}_{3}\right) .-\mathrm{HRMS}$ $((+)-\mathrm{FAB}): \quad \mathrm{m} / \mathrm{z}=671.4064$ (calcd. 671.4073 for $\left.\mathrm{C}_{41} \mathrm{H}_{60} \mathrm{O}_{5} \mathrm{~K},[\mathrm{M}+\mathrm{K}]^{+}\right)$.

\section{Acknowledgement}

We are grateful for financial support from the National Natural Science Foundation of China (81072551) and the Scientific Research Foundation for the Returned Overseas Chinese Scholars of Hebei Province (2006-02) and the Scientific Research Foundation of Hebei Province (08B032 and C2010000489). We also wish to thank for the financial support of Syngenta Ltd. (2011-Hebei Medical UniversitySyngenta-03) and grant-in-aid from Japan Society for the Promotion of Science (No. 22580112).
[1] E. Baloglu, D. G. I. Kingston, J Nat. Prod. 1999, 62, $1448-1472$.

[2] V. S. Parmer, A. Jha, K. S. Bish, P. Taneja, S. K. Sight,
A. Kumar, J. R. Poonam, C. E. Olsen, Phytochemistry 1999, 50, $1267-1304$.

[3] a) Q.-W. Shi, H. Kiyota, Chem. Biodivers. 2005, 
2, 1597-1623; b) Y.-F. Wang, Q. W. Shi, M. Dong, H. Kiyota, Y.-C. Gu, B. Cong, Chem. Rev. 10.1021/cr100147u.

[4] a) Y. L. Chow, H. Erdtman, Atta Chem. Scand. 1962, 16, 1296 - 1300; b) B.-L. Li, G.-H. Tian, Z.-G. Zhang, B. Liang, W. Wang, Chem. Nat. Compd. 2007, 43, $274-276$.

[5] Q.-W. Shi, T. Oritani, T. Sugiyama, Nat. Prod. Lett. 1999, 13, $105-112$.

[6] J. R. Hanson, Nat. Prod. Rep. 2007, 24, 1332 - 1341, and previous reports in the same series.

[7] P. Tane, K. E. Bergquist, B. Tene Ngadjui, J. Foyere Ayafer, O. Sternen, Tetrahedron 1995, 51, $11595-$ 11600.

[8] J. A. Takahashi, M. A. D. Boaventura, J. De Carvalho Bayma, A. B. Oliveira, Phytochemistry 1995, 40, 607 609, and refs. cited therein.

[9] T. Yoshida, M. Toyota, Y. Asakawa, Tetrahedron Lett. 1997, 38, 1975 - 1978.

[10] G. Suresh, K. Suresh Babu, M. Suri Appa Rao,
V. Rama Subba Rao, P. Ashok Yadav, V. Lakshma Nayak, S. Ramakrishna, Tetrahedron 2011, 52, 5016 5019.

[11] B. Galli, F. Gasparrini, V. Lanzotti, D. Misiti, R. Riccio, C. Villan, G.-f. He, Z.-w. Ma, W.-f. Yin, Tetrahedron 1999, 55, 11385 - 11394.

[12] I. Ara, B.S. Siddiqui, S. Faizi, S. Siddiqui, Phytochemistry 1990, 29, $911-914$.

[13] J. Liang, Z. Min, T. Tanaka, M. Mizuno, M. Iiyama, Huaxue Xuebao 1988, 46, 21 - 25.

[14] S.-H. Li, H.-J. Zhang, P. Yao, H.-D. Sun, Chin. Chem. Lett. 2001, 12, 429-430.

[15] B. Monacelli, G. Pasqua, B. Botta, V. Vinciguerra, E. Gacs-Baitz, G. Delle Monache, Planta Med. 2002, $68,764-766$.

[16] L.-Y. Wang, J. Bai, M. Kitabatake, J.-G. Dai, J. Sakai, J.-L. Wang, S.-J. Zhang, W.-X. Tang, L.-M. Bai, K. Hirose, M.-J. Li, T. Hasegawa, M. Ando, Curr. Top. Phytochemistry 2008, 9, 17-36. 